\title{
Hybrid additive manufacturing of steels and alloys
}

\author{
Vladimir V. Popov Jr.* and Alexander Fleisher \\ Israel Institute of Metals, Technion R\&D Foundation, Technion City, 3200003, Haifa, Israel
}

Received: 5 December 2019 / Accepted: 22 January 2020

\begin{abstract}
Hybrid additive manufacturing is a relatively modern trend in the integration of different additive manufacturing techniques in the traditional manufacturing production chain. Here the AM-technique is used for producing a part on another substrate part, that is manufactured by traditional manufacturing like casting or milling. Such beneficial combination of additive and traditional manufacturing helps to overcome well-known issues, like limited maximum build size, low production rate, insufficient accuracy, and surface roughness. The current paper is devoted to the classification of different approaches in the hybrid additive manufacturing of steel components. Additional discussion is related to the benefits of Powder Bed Fusion (PBF) and Direct Energy Deposition (DED) approaches for hybrid additive manufacturing of steel components.
\end{abstract}

\section{Introduction}

Additive manufacturing (AM) of metals and alloys is currently hard for mass production, due to insufficient built rate, limited maximum build size, issues of surface roughness, support structures removal, etc. However, AM-techniques overtop the possibilities of traditional manufacturing (like casting, Computer Numerical Control (CNC), etc.) in manufacturing net-shape-like structures and complex cooling channel systems.

The idea of hybrid AM came from the fact that a combination of traditional (subtractive) and additive manufacturing could help to overcome the limitations of both processes and to provide a new manufacturing approach for mass production of medium/big components with high geometrical complicity and accuracy.

To have a complete understanding of the hybrid material or technology, it is necessary to understand what does it means this term, which comes initially from the agronomy and bio-sciences. According to Cambridge Dictionary "hybrid (noun) a plant or animal that has been produced from two different types of plant or animal, especially to get better characteristics" or "hybrid (adjective) combines two different things". In the modern industrial world extremely sharp demand for new materials, which properties or combinations of properties expected to be beyond the state-of-the-art. This interest increased significantly in the past decade (see Fig. 1). To cover these needs is very often is not enough to use one single type of material or class of material or technology,

\footnotetext{
* e-mail: vvp@technion.ac.il
}

but to use a combination of multiple of it. In material science in the previous decade was used mainly "composite" term for characterization of such materials. But having of combination materials from different classes, for example, organic-inorganic [1]; bio-based-rubber [2]; metal-polymer [3]; steel-glass [4,5] the term "hybrid" became more often used to declare nature of the material type. To achieve unique properties or properties combinations researchers pay attention to hybrid materials design: for lightweight ceramic materials [6], lightweight and high-temperature resistant materials [7,8], metalceramic lightweight hybrid materials [9], hybrid polymer matrix composites [10,11], and hybrid metal-based composites [12-14]. The current extremely growing development of additive manufacturing processes allows starting implementing of combining different AM approaches together with traditional manufacturing to obtain hybrid materials with 3-dimensional sophisticated design. However, for the hybrid AM were published for a one order of magnitude less (2017-11; 2018-17 and 2019-24 papers, according to Science Direct database) in comparison with the Hybrid Technology and for two order of magnitude less than "Hybrid material" and "Hybrid Composites" (Fig. 1).

There are several 3D printing approaches that could be applied for industrial production of steel and other Febased alloys. The main two of them are Powder Bed Fusion (PBF) and Direct Energy Deposition (DED). Tables 1 and 2 present short classification of PBF and DED techniques, their benefits and applied materials.

Figure 2 schematically demonstrates the benefits of additive manufacturing (see Fig. 2c) in comparison with milling (see Fig. 2b) with high amount of wastes; and in 


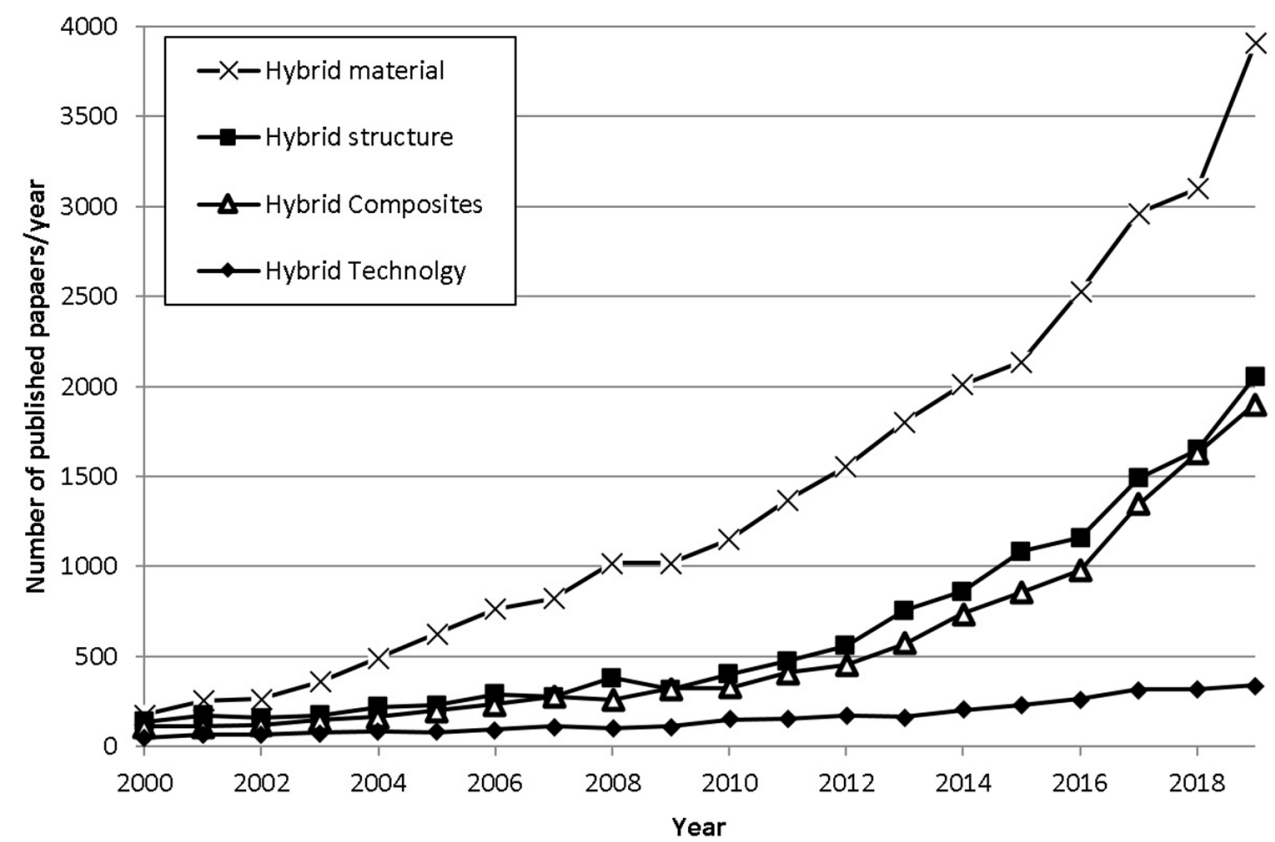

Fig. 1. Statistical data of number of published papers, by "Hybrid structure", "Hybrid material", "Hybrid Composites" and "Hybrid Technology" keywords. Data source - ScienceDirect ${ }^{\circledR}$, by Elsevier B.V.

Table 1. PBF techniques.

\begin{tabular}{|c|c|c|c|c|}
\hline Method & Benefits & Fe-based alloys & Other metals & References \\
\hline $\begin{array}{l}\text { Selective Laser } \\
\text { Sintering (SLS) }\end{array}$ & $\begin{array}{l}\text { Manufacturing of functional } \\
\text { polymer parts; } \\
\text { High accuracy and surface } \\
\text { quality compared to FDM } \\
\text { parts; }\end{array}$ & 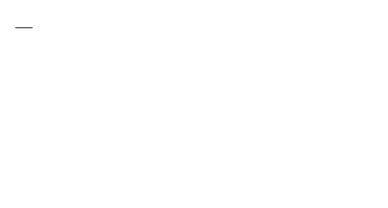 & $\begin{array}{l}\text { Nylon, PA, polymers, } \\
\text { polymer-based } \\
\text { composites }\end{array}$ & {$[15-17]$} \\
\hline $\begin{array}{l}\text { Selective Laser } \\
\text { Melting (SLM) }\end{array}$ & $\begin{array}{l}\text { High geometrical complicity } \\
\text { of the parts; } \\
\text { Higher accuracy compared to } \\
\text { EBM parts }\end{array}$ & $\begin{array}{l}\text { Stainless steel; } \\
\text { Tool steel; H13; } \\
\text { Maraging steel }\end{array}$ & $\begin{array}{l}\text { Ni-based super alloys; } \\
\text { Ti-alloys, Al-alloys; }\end{array}$ & {$[18-20]$} \\
\hline $\begin{array}{l}\text { Electron Beam } \\
\text { Melting (EBM) }\end{array}$ & $\begin{array}{l}\text { High geometrical complicity } \\
\text { of the parts; } \\
\text { No (extra low) residual stress; } \\
\text { Vacuum environment, no gas } \\
\text { infusions in the product; } \\
\text { Less amount of supports; }\end{array}$ & Stainless steel (SS316L) & $\begin{array}{l}\text { Ti-alloys; } \mathrm{Co}-\mathrm{Cr} ; \\
\text { Inconel } 625 ; \mathrm{TiAl}\end{array}$ & {$[21-25]$} \\
\hline $\begin{array}{l}\text { Binder Jetting } \\
\text { Printing (BJP) }\end{array}$ & $\begin{array}{l}\text { Geometrical complicity; } \\
\text { No supports; } \\
\text { Capability to produce Metal } \\
\text { Matrix Composites (MMCs) } \\
\text { and Ceramic Matrix } \\
\text { Composites (CMCs) }\end{array}$ & SS316L & Sand, ceramics & {$[26-28]$} \\
\hline
\end{tabular}

comparison with casting (see Fig. 2a), where for each geometrical change of the component, new high-cost diemold need to be developed and produced.

The current review aims to present the state-of-the-art in technological approaches, trends and limitations in steel materials hybrid additive manufacturing.

\section{Hybrid additive manufacturing}

Strong et al. discussed integrating additive manufacturing in supply chain together with traditional one. Authors demonstrated that such approach helps to implement freedom of design from AM into serial mass production [35]. 
Table 2. Direct Energy Deposition techniques.

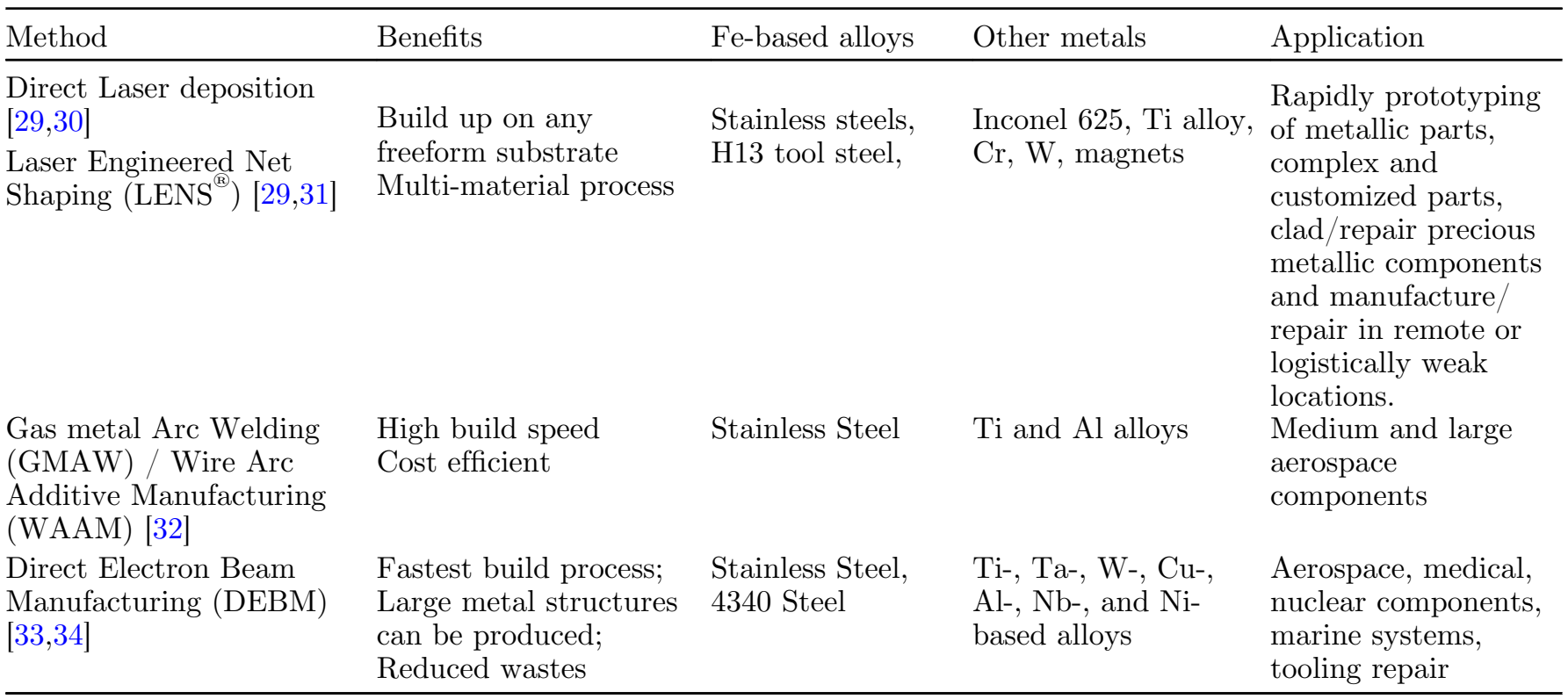

a

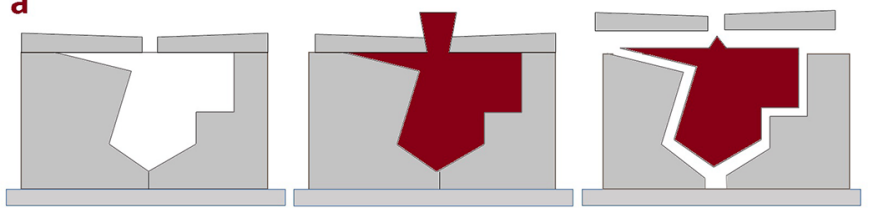

b
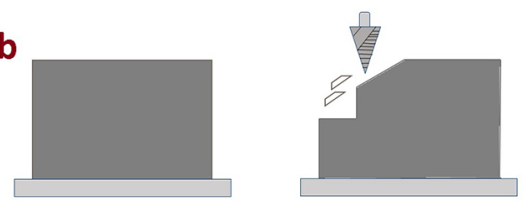

C
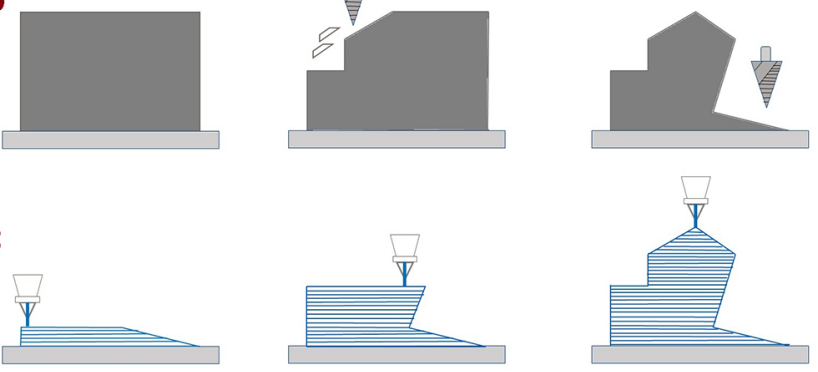

Fig. 2. Manufacturing techniques: 1-casting; 2-subtractive; 3 - additive manufacturing.

However in spite of very positive results of integrating AM with traditional manufacturing for super alloys and steels, this integration is still limited in industry. It can be explained by challenging adopting of process 3D printing parameters for each specific material and calibration according to geometry of substrate CNC part.

Merklein et al. stated that customization of lightweight geometrically complex constructions, of big size and high accuracy can be produced with the combination of additive and subtractive manufacturing processes within one single machine [30].

Oter et al. also demonstrated experimental findings in application of Selective Laser Sintering (SLM)/Direct Metal Laser Sintering (DMLS) - technique for hybrid AM of aluminum extrusion dies from hard hot steel [36]. The die-parts produced using hybrid AM can be utilized even with no post-processing.

Additive manufacturing is still not competitive to subtractive one in terms of surface quality and geometrical accuracy. That is why CNC is already often used as a postprinting step in a hybrid process for AM-parts. For example, in [42] it was reported about AIMS - hybrid process for metallic parts, where additive manufacturing process was completed with machining steps for support structures removal and surface finishing to overcome the limitation of typical lack of accuracy and surface roughness of printed parts. Such hybrid approach - AM+CNC allows to produce high precision parts via additive manufacturing.

In Table 3 are summarized different approaches in "hybridization" of manufacturing processes by combination of additive and subtractive, subtractive and additive, or additive and additive techniques.

\subsection{Powder Bed hybrid additive manufacturing}

By PBF usually determined several 3D printing techniques (see Tab. 1) that have the same principle of manufacturing: the use as a precursor of powder that is deposited layer-bylayer to the same layer thickness fused by laser, electron beam or binder in selected areas according cross-section of the CAD model $[18,48]$. Such powder depositing used for polymers in Selective Laser Sintering (SLS), for metals in Selective Laser Melting (SLM) and Electron Beam Melting (EBM), for ceramic and metallic powders in Binder Jetting Printing (BJP) [18].

For SLM and EBM are used commonly pre-alloyed spherical gas/plasma atomized powders; for BJP both spherical and irregular powders could be applied. 
Table 3. Hybrid additive manufacturing.

\begin{tabular}{llll}
\hline Combination & Fe-based alloys & Other metals & References \\
\hline AM upon CNC-part & Maraging and tool steels & & {$[36-39]$} \\
AM as a repairing of high-valued & $\begin{array}{l}\text { SS316L, tool steel, } \\
\text { maraging steel }\end{array}$ & Ti-alloys, Ni-alloys & {$[40,41]$} \\
$\begin{array}{l}\text { Components } \\
\text { parts }\end{array}$ & SS316L, tool steels & $\begin{array}{l}\text { Al6061; Ti-6Al-4V; Ni- } \\
\text { super-alloys; Brass }\end{array}$ & {$[42]$} \\
Combination of different AM types & SS316L & $\begin{array}{l}\text { Ti-alloys resin, polymers } \\
\text { (PLA, PET), ceramics; } \\
\text { Cu-alloys, Ni-alloys }\end{array}$ & {$[43-46]$} \\
Hybrid machine - single process & SS316L & Inconel & {$[47]$} \\
\hline
\end{tabular}

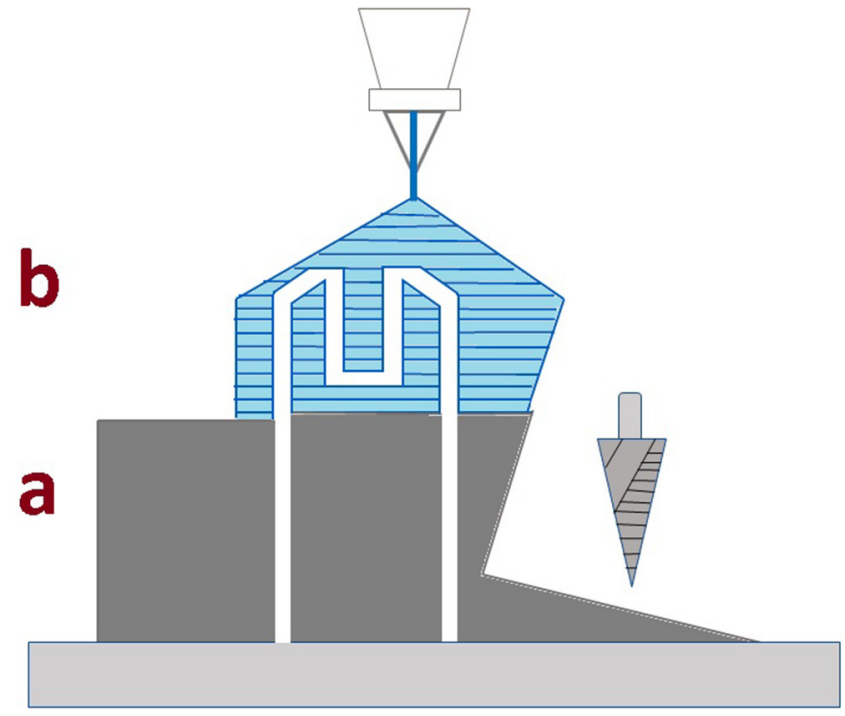

Fig. 3. Hybrid additive manufacturing.

BJP with further post-processing can be applied for production of hybrid CMC- and MMC-like materials [26,27].

Thus SLM (DMLS) process is beneficial for the manufacturing of small parts with relatively high accuracy, with the minimal size of elements up to 300 microns; internal channel geometry; lattices and similar lightweight net-shape structures, and complex heat-exchanger structures [18]. The applied heat treatment for stress relieving can be used for control of the final microstructure and mechanical properties.

In number of papers [36-39,49] it was demonstrated that SLM technique (EOS @ DMLS) can be effectively used for hybrid additive manufacturing of steel components for complex big size dies with internal cooling channel system.

Figure 3 illustrates the hybrid AM approach where the substrate part can be manufactured by traditional subtractive manufacturing, and the upper part with internal system of cooling channels - by additive manufacturing.
Paper [43] presents another SLM-integrated hybrid manufacturing process for production of biomedical dental implants. The mesh-shaped implants were manufactured from metal via SLM, with the further Stereolithography (SLA) process for coating of the mesh using liquid resin. This hybrid process with the use of two additive manufacturing techniques, allows to produce multimaterials with graded functional and structural properties.

SLM-manufactured parts can be also integrated in hybrid processes in combination with another AMtechniques. For example, in [44] it was shown how functional parts could be produced via SLM with Fusion Deposition Modelling (FDM). More than that it was demonstrated that not only metal+polymer structures could be produced, but even sandwich structures like metal + polymer + metal, which is beneficial for biomedical implants.

There were no found any reported data where EBM has been used in hybrid AM, as it is still seemed too complicated to print on some other substrate, except standard building platform, specific for each printed material. However PB-EBM using blended powders, including addition of ceramic nano-powder into metallic powder, can be the way for production of composite-like hybrid multi-materials [13,50,51].

\subsection{Direct energy deposition hybrid additive manufacturing}

According to the energy source used for direct metal deposition, wire-feed AM can be classified into three groups, namely: laser-based, arc welding based, and electron beam-based [52]. Arc welding based AM combines advantages of higher deposition rate, energy efficiency, safe operation, and lower cost, that made this system more promising comparing to laser-, and electron-beam-based systems [29] (see Tab. 4).

Gas Metal Arc-Welding (GMAW) 3D printing, also named as Wire Arc Additive Manufacturing (WAAM) [32], is closely related to single-layer multi-pass welding.

Table 4 demonstrates that energy efficiency of arc welding processes such as the Gas Metal Arc Welding (GMAW) or Gas Tungsten Arc Welding (GTAW) 
Table 4. Comparison of energy efficiency and deposition rate of DED processes.

\begin{tabular}{llll}
\hline DED process & Energy efficiency & Deposition rate & References \\
\hline WAAM - GMAW - GTAM & Up to $90 \%$ & $50-130 \mathrm{~g} / \mathrm{min}$ & {$[53-57]$} \\
Direct Laser Deposition, LENS & $2-5 \%$ & $2-10 \mathrm{~g} / \mathrm{min}$ & {$[53-55,58]$} \\
Direct Electron Beam Manufacturing (DEBM) & $15-20 \%$ & $2-10 \mathrm{~g} / \mathrm{min}$ & {$[53-55,59]$} \\
Direct Electron Beam Welding (DEBW) & & & \\
\hline
\end{tabular}
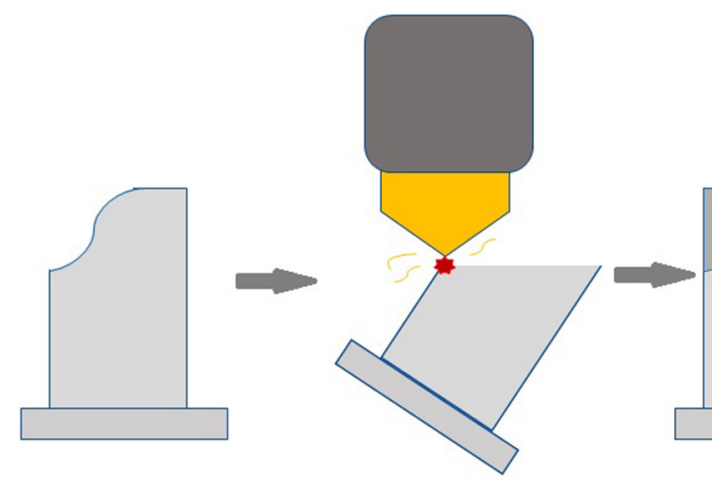

Fig. 4. Schematic view of repairing of turbine blade using DED technique.

processes can be up to $90 \%$ [56]. That is much higher comparing with the poor energy efficiency of laser and electron beam [56,57].

The same situation can be observed with the deposition rate - for laser/electron beam it is in the order of $2-10 \mathrm{~g} /$ min, compared with $50-130 \mathrm{~g} / \mathrm{min}$ for WAAM based technology.

The DED process, named as Laser Engineered Net Shaping $\left(\right.$ LENS $\left.^{\circledR}\right)$, became attractive and promising due to multiple nozzles, that resulted in a higher effectiveness of powder delivery, and enabled the use of several powders in one built $[60,61]$. Powder-based LENS $^{\circledR}$ can provide higher accuracy and lower surface roughness then WAAMtechniques. Moreover different powder compositions can be supplied using different nozzles for manufacturing hybrid and composite-like structures [62].

Electron beam has a slightly higher energy efficiency then LENS-process, but it requires a high vacuum working environment [59]. That fact limits the maximum size of the build by the size of building chamber.

One of the common advantages of DED-techniques in comparison with PBF techniques is the possibility to print on different substrates. It can be a different material, and also a non-flat surface. That enables the application of DED-techniques for repairing high-valuable components for critical safety applications like aerospace. Figure 4 schematically shows how the blade-like component can be re-newed using DED.

It can be concluded, that DED techniques using WAAM, DEBW, and LENS ${ }^{\circledR}$ are beneficial for hybrid AM in terms of surface defects repairing [40,41], productivity, rapid processing of weldable materials; manufacturing of medium and big components with complex geometry and internal configuration; and cost competitiveness [29,32,61].

\section{Steel and other Fe-based materials}

Steels and alloys with high iron concentration have strategical value for wide range of applications, like construction building, automotive, gas and oil industry, etc.

Iron-based alloys and high-alloyed steels remain attractive for many industries due too high mechanical properties, cutting, corrosion and wear resistance, ductility and hardness. These properties can be tailored according to application needs using alloying of additional elements in steels, and by different heat treatments.

\subsection{Stainless steels}

Additively manufactured stainless steel, mostly SS316L has been already reported in many papers $[24,25]$. Stainless steel manufactured by EBM even with no post-processing could be utilized for nuclear application [63].

SLM-made steels followed with the necessary postheat-treatment for stress relief and hardening, are used for medical components [64].

Stainless components can be either produced by BJP with the following post-sintering [27] for bone scaffolds or using infiltration for rotor and stator components [26,28].

All PBF techniques can be applied for components with complex net-shape structures. However, only SLM can be used for printing on the substrate part. EBM- and BJPmade parts can be used in hybrid AM as an alternative to traditional manufacturing in the production of substrate basic part. For example for composite or ceramic-based materials that are not possible (hardly possible) by SLM.

\subsection{Maraging and tool steels}

Tool steels are used for the production of wear-resistant and hard tools, and have significant differences from structural steels. By "tool steel" is considered such steel, which contain at least 0.7 percent carbon.

Between themselves, they differ in the presence of secondary carbides (they are not in hypereutectoid alloys). Moreover, carbides formed during eutectoid modifications or during the decay of martensite are necessarily present in all structures. 
Tool steel can be used for:

- Cold and hot deformation (stamping);

- High precision products;

- Cutting tool;

- Measuring products;

- High-pressure die-casting molds.

Maraging steels, typically containing Fe-65\%, Ni-18\%, Co- $8 \%$, are widely used in the tool and die industry due to their high specific strength, high fracture toughness and weldability. They are used for many tooling applications including plastic injection molding, high pressure diecasting, stumping, and extrusion dies [35,37].

Investigation of hybrid additive manufacturing of maraging and tool steel has been already reported by several papers [37-39,49,61,65]. SLM / DMLS was used for $3 \mathrm{D}$ printing. Hybrid AM of such type of steels used e.g. for die-casting inserts with complex cooling channels system: the substrate relatively simple shape part produced by machining, and then is put into SLM machine; calibration is performed according to cross-section of this part and building AM model.

\subsection{Protective coatings}

Application of protective coatings may bring an increase of corrosion and chemical resistance $[66,67]$, increase of working temperature of the products [68], improved wear resistance $[69,70]$ and, thus, longer lifetime of the product. Very high interest nowadays is on multi-layered structures [71-73] and high entropy alloy (HEA) coatings [73,74].

Deposition of such coatings also can be considered as a type of hybrid manufacturing where the part is produced by forging, milling or casting, and then thermal spray [75], or powder DED is applied.

In $\mathrm{PBF}$ approach deposition of metal coating on another alloy in one metallic component can be realized by filling the vertical hopper with two different powders (see Fig. 5) [51].

However this approach is far from industrialization, as it provides "coating" from the one specific layer, and it is more effective on flat objects. Actually it can be considered as a coating only on the flat objects, otherwise, it is a composite object with a gradient zone between two different metals (see Fig. 5).

\subsection{Hybrid and graded materials}

Manufacturing of hybrid-like compositionally and functionally graded materials is one of the modern unique options provided by the PBF-systems [13,76-78]. It can be achieved by simultaneous process parameters control and feeding of blended powders. Besides blended powders can contain different fractions, together metallic, ceramic, or polymer particles.

For such hybrid-like graded materials, additive manufacturing acts as a production technology. However, for homogeneous mixing of the blended powder before PBF again auxiliary traditional methods are applied.

Steel based Metal Matrix Composites (MMCs) can be produced by $\mathrm{PBF}$ techniques using blended powders

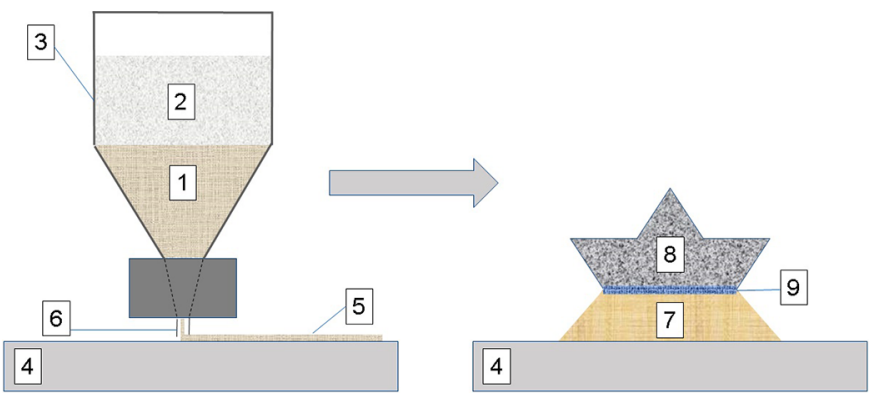

Fig. 5. Schematic view of hybrid PBF process using EBM system: 1-powder \#1;2-powder \#2;3-powder hopper for small amounts of powder; 4-building platform; 5-deposited powder layer; 6-rake blades for powder deposition; 7-part built from powder \#1; 8-part built from powder \#2; 9-gradient zone built from blended powder $\# 1+\# 2$.

$[13,50]$. Such an approach for manufacturing compositelike structures with hard abrasive surface and ductile inner part with reinforcement is discussed in [13].

\section{Summary}

The main common development trends of the state-of-theart of steel-based materials hybrid additive manufacturing routes can be extracted from the current review.

- Steel based materials are rapidly developing by PBF and DED techniques.

- There were reported several attempts to produce steelbased hybrid and composite materials using PBF techniques.

- DED techniques are more flexible in integration with the traditional CNC process. Such combination is beneficial for hybrid manufacturing, protective coatings and for parts repairing.

- Laser-based PBF allows hybrid additive manufacturing: the substrate simple-shape part is produced by traditional manufacturing and the complex shape one is printed directly on it.

In conclusion, it can be said, that hybrid additive manufacturing supposed to be a process that combines advantages of additive and subtractive manufacturing integrates AM into traditional production chain with compensating of AM limitations, resulting in an increase of $\mathrm{AM}$ processes industrialization.

We want to thank for the kind support and financial funding: COST Action CA15102, and the Office of the Chief Scientist of Israeli Ministry of Science and Technology.

\section{References}

1. D.K. Jesthi, R.K. Nayak, Evaluation of mechanical properties and morphology of seawater aged carbon and glass fiber reinforced polymer hybrid composites, Compos. B Eng. 174 (2019) 106980 
2. S.A. Kurnosenko, O.I. Silyukov, A.S. Mazur, I.A. Zvereva, Synthesis and thermal stability of new inorganic-organic perovskite-like hybrids based on layered titanates HLnTiO4 $(\mathrm{Ln}=\mathrm{La}, \mathrm{Nd})$, Ceram. Int. 4 (2019) 5058-5068

3. V. Lapkovskis, V. Mironovs, K. Irtiseva, D. Goljandin, Study of devulcanised crumb rubber-peat bio-based composite for environmental applications, Key Eng. Mater. 799 (2019) $148-152$

4. D.D. Luong, V.C. Shunmugasamy, N. Gupta, D. Lehmhus, J. Weise, J. Baumeister, Quasi-static and high strain rates compressive response of iron and Invar matrix syntactic foams, Mater. Des. 66 (2015) 516-531

5. L. Peroni et al., High strain rate tensile and compressive esting and performance of mesoporous invar (FeNi36) matrix syntactic foams produced by feedstock extrusion, Adv. Eng. Mater. 19 (2017) 1600474

6. K. Rugele, D. Lehmhus, I. Hussainova, J. Peculevica, M. Lisnanskis, A. Shishkin, Effect of ly-ash cenospheres on properties of clay-ceramic syntactic foams, Materials $\mathbf{1 0}$ (2017) 828

7. A. Shishkin, M. Drozdova, V. Kozlov, I. Hussainova, D. Lehmhus, Vibration-assisted sputter coating of cenospheres: a new approach for realizing $\mathrm{Cu}$-based metal matrix syntactic foams, Metals 7 (2017) 16

8. A. Shishkin, I. Hussainova, V. Kozlov, M. Lisnanskis, P. Leroy, D. Lehmhus, Metal-coated cenospheres obtained via magnetron putter coating: a new precursor for syntactic foams, JOM 70 (2018) 1319-1325

9. A. Shishkin, V. Mironov, V. Zemchenkov, M. Antonov, I. Hussainova, Hybrid syntactic foams of metal - fly ash cenosphere - clay, Key Eng. Mater. 674 (2016) 35-40

10. P. Vignesh, G. Venkatachalam, A. Gautham Shankar, A. Singh, R. Pagaria, A. Prasad, Studies on tensile strength of sugarcane fiber reinforced hybrid polymer matrix composite, Mater. Today Proc. 5 (2018) 13347-13357

11. J. Weise, A.F. Queiroz Barbosa, O. Yezerska, D. Lehmhus, J. Baumeister, Mechanical behavior of particulate aluminium-epoxy hybrid foams based on cold-setting polymers, Adv. Eng. Mater. 19 (2017) 1700090

12. R. Lapovok et al., Architectured hybrid conductors: aluminium with embedded copper helix, Mater. Des. 187 (2019) 108398. https://doi.org/10.1016/j.matdes.2019.108398

13. A. Koptyug et al., Compositionally-tailored steel-based materials manufactured by electron beam melting using blended pre-alloyed powders, Mater. Sci. Eng. A 771 (2019) 138587. https://doi.org/10.1016/j.msea.2019.138587

14. I. Todaro, R. Squatrito, S. Essel, H. Zeidler, High conductive aluminium metal matrix composites with carbon inserts obtained by casting processes, Mater. Today Proc. 10 (2019) 277-287

15. S. Song, Z. Gao, B. Lu, C. Bao, B. Zheng, L. Wang, Performance optimization of complicated structural $\mathrm{SiC} / \mathrm{Si}$ composite ceramics prepared by selective laser sintering, Ceram. Int. 46 (2020) 568-575

16. S. Singamneni et al., Selective laser sintering responses of keratin-based bio-polymer composites, Mater. Des. 183 (2019) 108087

17. R. Hong, Z. Zhao, J. Leng, J. Wu, J. Zhang, Two-step approach based on selective laser sintering for high performance carbon black/ polyamide 12 composite with 3D segregated conductive network, Compos. B Eng. 176 (2019) 107214
18. A. Katz-Demyanetz, V.V. Popov, A. Kovalevsky, D. Safranchik, A. Koptyug, Powder-bed additive manufacturing for aerospace application: Techniques, metallic and metal/ ceramic composite materials and trends, Manuf. Rev. 6 (2019) 5. https://doi.org/10.1051/mfreview/2019003

19. A. Adeyemi, E.T. Akinlabi, R.M. Mahamood, Powder bed based laser additive manufacturing process of stainless steel: a review, Mater. Today Proc. 5 (2018) 18510-18517

20. S. Afkhami, M. Dabiri, S.H. Alavi, T. Björk, A. Salminen, Fatigue characteristics of steels manufactured by selective laser melting, Int. J. Fatigue 122 (2019) 72-83

21. V.V. Popov, A. Katz-Demyanetz, A. Garkun, M. Bamberger, The effect of powder recycling on the mechanical properties and microstructure of electron beam melted Ti-6Al-4 V specimens, Addit. Manuf. 22 (2018) 834-843. https:// doi.org/10.1016/j.addma.2018.06.003

22. V.V. Popov et al., Effect of the hatching strategies on mechanical properties and microstructure of SEBM manufactured Ti-6Al-4V specimens, Lett. Mater. 8 (2018) 468-472. https://doi.org/10.22226/2410-3535-2018-4-468-472

23. C.J. Smith et al., Dimensional accuracy of electron beam melting (EBM) additive manufacture with regard to weight optimized truss structures, J. Mater. Process. Technol. 229 (2016) 128-138

24. A. Koptioug, L.E. Rännar, M. Bäckström, S.Z. Jian, New metallurgy of additive manufacturing in metal: experiences from the material and process development with electron beam melting technology (EBM), Mater. Sci. Forum 879 (2016) 996-1001

25. L.-E. Rännar, A. Koptyug, J. Olsén, K. Saeidi, Z. Shen, Hierarchical structures of stainless steel 316L manufactured by Electron Beam Melting, Addit. Manuf. 17 (2017) 106-112

26. A. Fleisher et al., Reaction bonding of silicon carbides by Binder Jet 3D-Printing, phenolic resin binder impregnation and capillary liquid silicon infiltration, Ceram. Int. 45 (2019) 18023-18029. https://doi.org/10.1016/j.ceramint.2019.06.021

27. S. Vangapally, K. Agarwal, A. Sheldon, S. Cai, Effect of lattice design and process parameters on dimensional and mechanical properties of binder jet additively manufactured stainless steel 316 for bone scaffolds, Procedia Manuf. 10 (2017) 750-759

28. M. Doyle, K. Agarwal, W. Sealy, K. Schull, Effect of layer thickness and orientation on mechanical behavior of binder jet stainless steel $420+$ bronze Parts, Procedia Manuf. 1 (2015) 251-262

29. S.M. Thompson, L. Bian, N. Shamsaei, A. Yadollahi, An overview of Direct Laser Deposition for additive manufacturing; Part I: Transport phenomena, modeling and diagnostics, Addit. Manuf. 8 (2015) 36-62

30. M. Merklein, D. Junker, A. Schaub, F. Neubauer, Hybrid additive manufacturing technologies - an analysis regarding potentials and applications, Phys. Procedia 83 (2016) 549-559

31. E.M. White, A.G. Kassen, E. Simsek, W. Tang, R.T. Ott, I. E. Anderson, Net shape processing of alnico magnets by additive manufacturing, IEEE Transac. Magn. 53 (2017) 1-6

32. D. Ding, Z. Pan, D. Cuiuri, H. Li, A multi-bead overlapping model for robotic wire and arc additive manufacturing (WAAM), Robot. Comput. Integr. Manuf. 31 (2015) $101-110$ 
33. M.T. Stawovy, Comparison of LCAC and PM Mo deposited using Sciaky EBAM ${ }^{\mathrm{TM}}$, Int. J. Refract. Met. Hard Mater. 73 (2018) 162-167

34. Sciaky Inc., Official web-site of Sciaky Inc. [Online]. Available: https://www.sciaky.com/eb-welding-systems/ electron-beam-welding-solutions.

35. D. Strong, M. Kay, B. Conner, T. Wakefield, G. Manogharan, Hybrid manufacturing - integrating traditional manufacturers with additive manufacturing (AM) supply chain, Addit. Manuf. 21 (2018) 159-173

36. Z.C. Oter et al., Benefits of laser beam based additive manufacturing in die production, Optik 176 (2019) 175-184

37. H. Azizi et al., Metallurgical and mechanical assessment of hybrid additively-manufactured maraging tool steels via selective laser melting, Addit. Manuf. 27 (2019) 389-397

38. A. Ebrahimi, M. Mohammadi, Numerical tools to investigate mechanical and fatigue properties of additively manufactured MS1-H13 hybrid steels, Addit. Manuf. 23 (2018) 381-393

39. S. Shakerin, A. Hadadzadeh, B.S. Amirkhiz, S. Shamsdini, J. Li, M. Mohammadi, Additive manufacturing of maraging steel-H13 bimetals using laser powder bed fusion technique, Addit. Manuf. 29 (2019) 100797

40. M. Praniewicz, T. Kurfess, C. Saldana, Adaptive geometry transformation and repair for hybrid manufacturing, Procedia Manufacturing 26 (2018) 228-236

41. Y. Li, Q. Han, I. Horváth, G. Zhang, Repairing surface defects of metal parts by groove machining and wire + arc based filling, J. Mater. Process. Technol. 274 (2019) 116268

42. G. Manogharan, R. Wysk, O. Harrysson, R. Aman, AIMS A metal additive-hybrid manufacturing system: system architecture and attributes, Procedia Manuf. 1 (2015) 273-286

43. M. Silva, R. Felismina, A. Mateus, P. Parreira, C. Malça, Application of a hybrid additive manufacturing methodology to produce a metal/polymer customized dental implant, Procedia Manuf. 12 (2017) 150-155

44. Y.-H. Chueh, C. Wei, X. Zhang, L. Li, Integrated laser-based powder bed fusion and fused filament fabrication for threedimensional printing of hybrid metal/polymer objects, Addit. Manuf. 31 (2020) 100928

45. X. Shi et al., Selective laser melting-wire arc additive manufacturing hybrid fabrication of Ti-6Al-4V alloy: Microstructure and mechanical properties, Mater. Sci. Eng. A 684 (2017) 196-204

46. C.J. Huang et al., Additive manufacturing hybrid Ni/Ti-6Al$4 \mathrm{~V}$ structural component via selective laser melting and cold spraying, Vacuum 151 (2018) 275-282

47. T. Yamazaki, Development of a hybrid multi-tasking machine tool: integration of additive manufacturing technology with CNC machining, Procedia CIRP 42 (2016) 81-86

48. A. Leon, G.K. Levy, T. Ron, A. Shirizly, E. Aghion, The effect of hot isostatic pressure on the corrosion performance of Ti- $6 \mathrm{Al}-4 \mathrm{~V}$ produced by an electron-beam melting additive manufacturing process, Addit. Manuf. (2020) 101039

49. E. Cyr, H. Asgari, S. Shamsdini, M. Purdy, K. Hosseinkhani, M. Mohammadi, Fracture behaviour of additively manufactured MS1-H13 hybrid hard steels, Mater. Lett. 212 (2018) $174-177$

50. A. Koptyug, M. Bäckström, C.A. Botero Vega, V.V. Popov, E. Chudinova, Developing new materials for electron beam melting: experiences and challenges, Mater. Sci. Forum 941 (2018) 2190-2195. https://doi.org/10.4028/www.scientific. net/MSF.941.2190
51. A. Koptyug, L.-E. Rännar, C. Botero, M. Bäckström, V. Popov, Blended powders can be successfully used in Electron Beam Melting yielding unique material compositions, in EuroPM2018 Proceedings, EPMA, Shrewsbury, 2018

52. K.P. Karunakaran, S. Suryakumar, V. Pushpa, S. Akula, Low cost integration of additive and subtractive processes for hybrid layered manufacturing, Robot. Comput. Integr. Manuf. 26 (2010) 490-499

53. J. Mazumder, D. Dutta, N. Kikuchi, A. Ghosh, Closed loop direct metal deposition: art to part, Opt. Lasers Eng. 34 (2000) 397-414

54. P. Wanjara, M. Brochu, M. Jahazi, Electron beam freeforming of stainless steel using solid wire feed, Mater. Des. 28 (2007) 2278-2286

55. A. Sreenathbabu, K.P. Karunakaran, C. Amarnath, Statistical process design for hybrid adaptive layer manufacturing, Rapid Prototyp. J. 11 (2005) 235-248

56. J.N. DuPont, A.R. Marder, Thermal efficiency of arc welding processes, Weld. J. 74 (1995) 406

57. N. Stenbacka, I. Choquet, K. Hurtig, Review of Arc Efficiency Values for Gas Tungsten Arc Welding, IIW Commission IV-XII-SG212 Intermediate Meeting, Berlin, Germany, 2012, pp. 1-21

58. R.R. Unocic, J.N. DuPont, Process efficiency measurements in the laser engineered net shaping process, Metall. Mater. Trans. B Process Metall. Mater. Process. Sci. 35 (2004) $143-152$

59. L.E. Rannar, A. Glad, C.G. Gustafson, Efficient cooling with tool inserts manufactured by electron beam melting, Rapid Prototyp. J. 13 (2007) 128-135

60. K.-H. Chang, K.-H. Chang, Rapid Prototyping, e-Design, Academic Press, Boston, MA, 2015, pp. 743-786

61. X. Zhang, G. Mi, C. Wang, Microstructure and performance of hybrid laser-arc welded high-strength low alloy steel and austenitic stainless steel dissimilar joint, Opt. Laser Technol. 122 (2020) 105878

62. Y. Zhang, A. Bandyopadhyay, Direct fabrication of compositionally graded Ti-Al2O3 multi-material structures using Laser Engineered Net Shaping, Addit. Manuf. 21 (2018) 104-111

63. Y. Zhong et al., Additive manufacturing of 316L stainless steel by electron beam melting for nuclear fusion applications, J. Nucl. Mater. 486 (2017) 234-245

64. T. Zhong, K. He, H. Li, L. Yang, Mechanical properties of lightweight 316L stainless steel lattice structures fabricated by selective laser melting, Mater. Des. 181 (2019) 108076

65. F. Klocke, K. Arntz, M. Teli, K. Winands, M. Wegener, S. Oliari, State-of-the-art Laser Additive Manufacturing for Hot-work Tool Steels, Procedia CIRP 63 (2017) 58-63

66. A.D. Pogrebnyak et al., Properties and structure of oxidized coatings deposited onto Al-Cu and Al-Mg alloys, Tech. Phys. 57 (2012) 840-848

67. M.Y. Rekha, C. Srivastava, Microstructure and corrosion properties of zinc-graphene oxide composite coatings, Corros. Sci. 152 (2019) 234-248

68. O.V. Bondar et al., Fabrication and research of superhard (Zr-Ti-Cr-Nb)N Coatings, Acta Phys. Pol. A 128 (2015) $867-870$

69. J. Nohava, P. Dessarzin, P. Karvankova, M. Morstein, Characterization of tribological behavior and wear mechanisms of novel oxynitride PVD coatings designed for applications at high temperatures, Tribol. Int. 81 (2015) 231-239 
70. Z. Lei et al., Corrosion performance of $\mathrm{ZrN} / \mathrm{ZrO}_{2}$ multilayer coatings deposited on 304 stainless steel using multi-arc ion plating, Appl. Surf. Sci. 431 (2018) 170-176

71. B.O. Postolnyi, P. Konarski, F.F. Komarov, O.V. Sobol', O.V. Kyrychenko, D.S. Shevchuk, Study of elemental and structural phase composition of multilayer nanostructured TiN / MoN coatings, their physical and mechanical properties, J. Nano- Electron. Phys. 6 (2014) 4

72. Y. Shi, B. Yang, P.K. Liaw, Corrosion-resistant high-entropy alloys: A review, Metals 7 (2017) 1-18

73. W. Li, P. Liu, P. K. Liaw, Microstructures and properties of high-entropy alloy films and coatings: A review, Mater. Res. Lett. 6 (2018) 199-229

74. A. López-Ortega, J.L. Arana, E. Rodríguez, R. Bayón, Corrosion, wear and tribocorrosion performance of a thermally sprayed aluminum coating modified by plasma electrolytic oxidation technique for offshore submerged components protection, Corros. Sci. 143 (2018) 258-280
75. Y. Wang, L. Zhang, S. Daynes, H. Zhang, S. Feih, M.Y. Wang, Design of graded lattice structure with optimized mesostructures for additive manufacturing, Mater. Des. 142 (2018) 114-123

76. V.V. Popov, A. Katz-Demyanetz, A. Koptyug, M. Bamberger, Selective electron beam melting of Al0.5CrMoNbTa0.5 high entropy alloys using elemental powder blend, Heliyon 5 (2019) e01188. https://doi.org/10.1016/j. heliyon.2019.e01188

77. S. Yin, X. Yan, C. Chen, R. Jenkins, M. Liu, R. Lupoi, Hybrid additive manufacturing of Al-Ti6Al4V functionally graded materials with selective laser melting and cold spraying, J. Mater. Process. Technol. 255 (2018) 650-655

78. C. Tan, K. Zhou, W. Ma, L. Min, Interfacial characteristic and mechanical performance of maraging steel-copper functional bimetal produced by selective laser melting based hybrid manufacture, Mater. Des. 155 (2018) 77-85

Cite this article as: Vladimir V. Popov Jr., Alexander Fleisher, Hybrid additive manufacturing of steels and alloys, Manufacturing Rev. 7, 6 (2020) 